\title{
Effects of gamma-irradiation of seed potatoes on numbers of stems and tubers
}

\author{
A. J. HAVERKORT ${ }^{1}$, D. I. LANGERAK ${ }^{2} \&$ M. VAN DE WAART ${ }^{1}$ \\ ${ }^{1}$ Centre for Agrobiological Research (CABO-DLO), P.O. Box 14, NL 6700 AA Wagenin- \\ gen, Netherlands \\ ${ }_{2}^{2}$ State Institute for Quality Control of Agricultural Products (RIKILT), P.O. Box 230, NL \\ 6700 AE Wageningen, Netherlands
}

Received 28 november 1990; accepted 8 February 1991

\begin{abstract}
In field trials with the cultivars Bintje, Jaerla and Spunta, whose seed potatoes were treated with gamma-rays from a ${ }^{60} \mathrm{Co}$ source with doses varying from 0.5 to $27 \mathrm{~Gy}$, tuber yield, harvest index, and number of stems and tubers were determined. A dose of 3 Gy increased the number of tubers by $30 \%$ in Spunta in two out of three trials and by $17 \%$ in one trial in Jaerla, but it did not increase number of tubers in Bintje. Doses of 9 or $10 \mathrm{~Gy}$ did not influence the number of tubers nor stems, and decreased harvest index. A dose of $27 \mathrm{~Gy}$ yielded off-type plants with reduced yield and number of tubers. Gamma-radiation affected the growth of the apex of the sprout allowing lateral buds or divisions of the affected apex to develop into stems. To achieve larger numbers of tuber-bearing stems, tubers should preferably be irradiated at the start of sprout growth, about 5 months before planting.
\end{abstract}

Keywords: harvest index, gamma irradiation, seed potatoes

\section{Introduction}

Effects of different doses of gamma-rays on potato tubers have been studied extensively, especially in the 1960 s. For convenience, all previously reported doses and dose equivalents in the literature given in rads or rems were converted into grays (Gy): $1 \mathrm{~Gy}=1 \mathrm{~J} \mathrm{~kg}^{-1}=100 \mathrm{rad}=100 \mathrm{rem}$. Most reports concern the effect of reduced sprouting during potato storage aimed at a prolongation of the storage period after harvest for consumption and processing potatoes. Sawyer \& Dallyn (1961) reported that commercial control of sprouting for a long duration could be obtained with doses of 75 to $125 \mathrm{~Gy}$, depending on cultivar.

Cotter \& Sawyer (1961), however, found an increase in storage rot with higher doses as well as in the physiological disorder black spot characterized by variable amount of subsurface black discoloration. They were associated with reduced content of ascorbic acid, the more so with higher dose. Similar results were reported by Sparks \& Iritani (1964) with cultivar Russet Burbank potato tubers treated with 50 to $200 \mathrm{~Gy}$ which could be stored for up to 500 days and by Wills (1965) with several 
cultivars treated with doses varying from 50 to $100 \mathrm{~Gy}$. Wills, however, found storage to have a worse effect on content of ascorbic acid than irradiation, which stabilized or even increased content of ascorbic acid.

From the same period come the first comprehensive reports on gamma-radiation of seed tubers to influence the crops planted with them. Fischnich et al. (1961) found that seed tubers treated with gamma-rays at up to $1 \mathrm{~Gy}$ usually showed enhanced sprouting if tuber metabolism was stimulated by temperatures near $18{ }^{\circ} \mathrm{C}$ before and after irradiation. Heilinger et al. (1967) investigated the effect of two doses $(0.1$ and $1 \mathrm{~Gy})$ of three sources $\left({ }^{137} \mathrm{Cs},{ }^{60} \mathrm{Co}\right.$ and $\mathrm{X}$-ray $) 5$ days before planting seed tubers at three sites. Irradiation prolonged the time between planting and emergence and reduced the height of the plants. The number of tubers per plant was increased at one site after $1 \mathrm{~Gy}$ of $\mathrm{X}$-rays, whereas $1 \mathrm{~Gy}$ from the ${ }^{137} \mathrm{Cs}$ source resulted in a significant decrease in the number of tubers per plant. On another site, gamma-rays from ${ }^{137} \mathrm{Cs}$ significantly increased the number of tubers per plant. Tuber yields were not influenced with either dose from either source on either site. Even though these results are not conclusive, they indicate that irradiation of potato seed tubers may alter certain plant characteristics under certain conditions. Voropaev et al. (1968) found increased yields of potatoes growing in pots after a dose of gamma-rays of 1.5 or $10 \mathrm{~Gy}$. Both doses increased yields when given one month before planting but the higher dose decreased yield when applied just before planting.

The field trials presented in this paper were carried out at the Droevendaal Experimental Farm of the Centre for Agrobiological Research (CABO-DLO) in Wageningen. The objectives were:

- to study the possible use of gamma-rays to increase the number of tubers of cultivars that usually produce only a few tubers per plant;

- to validate some of the results reported by previous authors;

- to elucidate the mechanism through which gamma-rays influences number of stems and tubers.

\section{Materials and methods}

Tubers were treated with gamma-rays from a ${ }^{60} \mathrm{Co}$ source at the Pilot Plant for Food Irradiation in Wageningen. Seed potatoes of the cultivars Bintje, Jaerla and Spunta were left in rotating containers $2 \mathrm{~m}$ from a gamma source with a dose rate of 1000 $\mathrm{Gy} \mathrm{h}^{-1}$. In 1988, 1989 and 1990, the tubers were planted in three field trials on the experimental farm.

Fertilizers were applied according to recommendations for seed potatoes and water was supplied according to evaporative demands by means of an overhead sprinkler. The experimental details are given in Table 1.

Trial 1 (1988) used seed potatoes of the cultivars Bintje and Spunta, half of which were chitted for 66 days at $12{ }^{\circ} \mathrm{C}$ in the light of TL-33 (Philips) lamps with an irradiance of $50 \mathrm{~W} \mathrm{~m}^{-2}$ at tuber level. The unchitted controls were left at $4{ }^{\circ} \mathrm{C}$ in the dark. Doses of gamma-rays were as indicated in Table 1, at the beginning of the chitting period or on the day of planting. 
Table 1. Experimental conditions.

\begin{tabular}{|c|c|c|c|}
\hline Detail & Trial 1 & Trial 2 & Trial 3 \\
\hline Year & 1988 & 1989 & 1990 \\
\hline Cultivar(s) & Bintje, Spunta & Spunta & Spunta, Jaerla \\
\hline Size of seed tuber $(\mathrm{mm})$ & $35-45$ & $35-45$ & $40-45$ \\
\hline \multicolumn{4}{|l|}{ Doses (Gy): } \\
\hline D1 & 0 & 0 & 0 \\
\hline D2 & 3 & 0.5 & 3 \\
\hline D3 & 9 & 3 & 10 \\
\hline D4 & 27 & & \\
\hline \multicolumn{4}{|l|}{ Radiation dates: } \\
\hline $\mathrm{T} 1$ & $12-02-88$ & $02-09-88$ & $25-10-89$ \\
\hline $\mathrm{T} 2$ & $21-04-88$ & $01-11-88$ & \\
\hline T3 & & $03-01-89$ & \\
\hline T4 & & 03-03-89 & \\
\hline Presprouting date & $15-02-88$ & $15-03-89$ & $16-03-90$ \\
\hline Planting date & $21-04-88$ & $20-04-89$ & $12-04-90$ \\
\hline Harvest date & $29-07-88$ & $26-07-89$ & $25-07-90$ \\
\hline Number of replicates & 2 & 4 & 4 \\
\hline Number of rows per plot & 5 & 1 & 6 \\
\hline Row length $(\mathrm{m})$ & 2.7 & 3.2 & 2.7 \\
\hline Plant distance in row $(\mathrm{cm})$ & 30 & 23 & 30 \\
\hline \multicolumn{4}{|l|}{ Net number of plants } \\
\hline harvested per plot & 21 & 12 & 28 \\
\hline
\end{tabular}

Trial 2 involved the cultivar Spunta planted in single-row plots. Different lots of seed potatoes were treated with doses of 0.5 or $3 \mathrm{~Gy}$ at intervals of two months from 2 September 1988 onwards. Before and after the treatments, the test lots and the controls (which were also removed from the cold store to be submitted to the same temperature and transport conditions as the treated tubers) were left at $4{ }^{\circ} \mathrm{C}$ in the dark until 36 days before planting. They were then subject to the same chitting conditions as in Trial 1.

Trial 3 (1990) was with seed potatoes of the cultivars Jaerla and Spunta. They were irradiated directly from cold storage at doses of 0,3 or $10 \mathrm{~Gy}$ on 25 October 1989. To hasten the development of sprouts of the seed tubers stored in the dark at $4{ }^{\circ} \mathrm{C}$ before and after irradiation, the seed tubers were submitted to 3 days of warmth at $20^{\circ} \mathrm{C}$ in the dark before subjection for 24 days to the chitting conditions described before.

In Trials 2 and 3, the number of plants emerging was recorded daily. From these data, the time between planting and $80 \%$ emergence was derived. After harvest at the normal time for seed-potato production in the last week of July, the number of main stems and tubers per plot were counted; the total mass of fresh haulms and tubers were determined as well as their content of dry matter after drying for 24 hours at $105^{\circ} \mathrm{C}$.

The data were analysed for variance (ANOVA) leading to an indication of significant differences between means and to significant interaction between factors in 
the trials. These significances are shown in Tables 2 to 5 . Where there was interaction, the main effects were not relevant. In the section Results and discussion, any interactions are explained and discussed.

\section{Results and discussion}

The two cultivars Bintje and Spunta reacted differently to irradiation (Table 2 for Bintje; Table 3 for Spunta). The number of tubers per plant of the cultivar Bintje was not significantly increased by 3 or $9 \mathrm{~Gy}$, but $27 \mathrm{~Gy}$ led to a strong reduction in number. When the treatment took place on the day of planting, this reduction was mainly due to a reduced number of stems. When treated with $27 \mathrm{~Gy}$ before chitting, it was mainly due to a reduced number of tubers per stem. The damage done to the seed tubers by the high dose in their ability to produce stems apparently was partly

Table 2. Effects of chitting and time and dose of radiation on yield characteristics of cv. Bintje (Trial 1, 1988). See Table 1 for experimental details.

\begin{tabular}{|c|c|c|c|c|c|c|c|}
\hline $\begin{array}{l}\text { Dose } \\
\text { (Gy) }\end{array}$ & Time & $\operatorname{Pr}$ & $\begin{array}{l}\text { Number } \\
\text { tu/pl }\end{array}$ & $\begin{array}{l}\text { Number } \\
\text { st/pl }\end{array}$ & $\begin{array}{l}\text { Number } \\
\text { tu/st }\end{array}$ & $\begin{array}{l}\text { Tu wt } \\
(\mathrm{g}) / \mathrm{pl}\end{array}$ & $\mathrm{HI}$ \\
\hline 0 & \multirow[t]{4}{*}{$\mathrm{T} 1$} & \multirow[t]{4}{*}{ no } & 22.3 & 6.57 & 3.39 & 1230 & 0.711 \\
\hline 3 & & & 20.9 & 6.96 & 2.95 & 1230 & 0.681 \\
\hline 9 & & & 22.0 & 6.88 & 2.95 & 1202 & 0.630 \\
\hline 27 & & & 10.7 & 6.21 & 1.68 & 572 & 0.522 \\
\hline 0 & \multirow[t]{4}{*}{$\mathrm{T} 2$} & \multirow[t]{4}{*}{ no } & 20.3 & 7.00 & 2.93 & 1326 & 0.703 \\
\hline 3 & & & 20.7 & 6.00 & 3.52 & 1122 & 0.688 \\
\hline 9 & & & 20.0 & 8.43 & 2.48 & 1017 & 0.647 \\
\hline 27 & & & 7.6 & 3.91 & 1.94 & 597 & 0.691 \\
\hline 0 & \multirow[t]{4}{*}{ T1 } & \multirow[t]{4}{*}{ yes } & 22.1 & 4.84 & 4.59 & 1421 & 0.768 \\
\hline 3 & & & 22.9 & 4.36 & 5.31 & 1412 & 0.799 \\
\hline 9 & & & 20.6 & 5.50 & 3.74 & 1381 & 0.788 \\
\hline 27 & & & 22.8 & 6.29 & 3.63 & 1195 & 0.751 \\
\hline 0 & \multirow[t]{4}{*}{$\mathrm{T} 2$} & \multirow[t]{4}{*}{ yes } & 22.7 & 5.87 & 3.75 & 1472 & 0.802 \\
\hline 3 & & & 19.8 & 5.45 & 3.61 & 1412 & 0.774 \\
\hline 9 & & & 16.3 & 4.29 & 3.80 & 1305 & 0.776 \\
\hline 27 & & & 11.9 & 3.63 & 3.32 & 812 & 0.750 \\
\hline \multicolumn{3}{|l|}{$\overline{\mathrm{Do}}$} & +++ & ns & $*$ & $* * *$ & NS \\
\hline \multicolumn{3}{|l|}{$\mathrm{Pr}$} & ++ & ++ & $* * *$ & $* * *$ & $* * *$ \\
\hline \multicolumn{3}{|l|}{$\mathrm{Ti}$} & $* *$ & NS & NS & NS & NS \\
\hline \multicolumn{3}{|c|}{$\operatorname{Pr} \times \mathrm{Ti}$} & * & NS & NS & NS & NS \\
\hline \multicolumn{3}{|c|}{$\mathrm{Do} \times \mathrm{Pr}$} & $* * *$ & NS & NS & NS & NS \\
\hline \multicolumn{3}{|c|}{$\mathrm{Do} \times \mathrm{Ti}$} & * & * & NS & NS & NS \\
\hline \multicolumn{3}{|c|}{ Do $\times \operatorname{Pr} \times \mathrm{Ti}$} & NS & NS & NS & NS & NS \\
\hline
\end{tabular}

$\mathrm{Pr}=$ chitting; Do $=$ dose of gamma-rays; $\mathrm{Ti}=$ time of irradiation (1) before chitting and (2) after chitting; tu = tuber; $\mathrm{pl}=$ plant; $\mathrm{st}=\mathrm{stem}$; $\mathrm{wt}=$ weight; $\mathrm{HI}=$ harvest index; ${ }^{* *} P<0.001 ;{ }^{* *} P<0.01$; ${ }^{*} P<0.1$; NS $=$ not significant;,,++++++ and ns: significancies of main effects where interaction exists. 
restored during chitting, whereas such recovery did not take place when the seed tubers were placed at $4{ }^{\circ} \mathrm{C}$ after gamma-ray treatment. The highest dose caused irreparable damage to the seed tubers; it caused the plants to emerge later (exact time not recorded in 1988) and led to dwarfed off-type plants.

Irradiation with a dose of $3 \mathrm{~Gy}$ increased numbers of tubers per plant with the cultivar Spunta, which usually produces few tubers (Table 3). The effect on the number of stems per plant were greatest when the treatment took place before chitting. The increase in number of tubers per plant caused by irradiation was enhanced by chitting. As for Bintje, the highest dose of $27 \mathrm{~Gy}$ on the day of planting reduced the number of tubers per plant by reducing the number of tubers per stem. Irradiation with $27 \mathrm{~Gy}$ reduced number of stems per plant when treated before chitting. The increase in number of tubers per plant was about $30 \%$ in the T2 chitted and in the T1 chitted treatments. The mean weight per tuber was increased by chitting and decreased by the highest dose of gamma-rays. This effect was associated with a corresponding increase or decrease in harvest index, indicating that chitting led to more

Table 3. Effects of chitting, time and dose of gamma-rays on yield characteristics of cv. Spunta (Trial 1, 1988). See Tables 1 and 2 for experimental details and abbreviations.

\begin{tabular}{|c|c|c|c|c|c|c|c|}
\hline $\begin{array}{l}\text { Dose } \\
\text { (Gy) }\end{array}$ & Time & $\operatorname{Pr}$ & $\begin{array}{l}\text { Number } \\
\mathrm{tu} / \mathrm{pl}\end{array}$ & $\begin{array}{l}\text { Number } \\
\text { st/pl }\end{array}$ & $\begin{array}{l}\text { Number } \\
\text { tu/st }\end{array}$ & $\begin{array}{l}\text { Tu wt } \\
(\mathrm{g}) / \mathrm{pl}\end{array}$ & $\mathrm{HI}$ \\
\hline 0 & \multirow[t]{4}{*}{$\mathrm{T} 1$} & \multirow[t]{4}{*}{ no } & 12.9 & 4.21 & 2.92 & 1236 & 0.679 \\
\hline 3 & & & 14.4 & 4.57 & 3.16 & 1266 & 0.725 \\
\hline 9 & & & 10.9 & 4.61 & 2.35 & 1099 & 0.646 \\
\hline 27 & & & 5.9 & 4.43 & 1.37 & 554 & 0.431 \\
\hline 0 & \multirow[t]{4}{*}{$\mathrm{T} 2$} & \multirow[t]{4}{*}{ no } & 12.3 & 3.79 & 3.07 & 1187 & 0.684 \\
\hline 3 & & & 15.9 & 4.91 & 3.27 & 1287 & 0.685 \\
\hline 9 & & & 9.8 & 5.00 & 1.98 & 1041 & 0.643 \\
\hline 27 & & & 6.2 & 2.79 & 2.15 & 490 & 0.426 \\
\hline 0 & \multirow[t]{4}{*}{ T1 } & \multirow[t]{4}{*}{ yes } & 13.4 & 3.71 & 3.54 & 1520 & 0.739 \\
\hline 3 & & & 17.7 & 4.84 & 3.76 & 1596 & 0.761 \\
\hline 9 & & & 14.0 & 3.94 & 3.71 & 1496 & 0.756 \\
\hline 27 & & & 16.2 & 5.53 & 2.93 & 1474 & 0.753 \\
\hline 0 & \multirow[t]{4}{*}{$\mathrm{T} 2$} & \multirow[t]{4}{*}{ yes } & 14.9 & 3.93 & 3.99 & 1684 & 0.753 \\
\hline 3 & & & 14.9 & 4.31 & 3.51 & 1630 & 0.765 \\
\hline 9 & & & 17.2 & 4.00 & 4.30 & 1504 & 0.771 \\
\hline 27 & & & 8.5 & 3.36 & 2.38 & 720 & 0.656 \\
\hline \multicolumn{3}{|l|}{ Do } & +++ & ns & $* *$ & +++ & +++ \\
\hline \multirow{2}{*}{\multicolumn{3}{|c|}{$\begin{array}{l}\mathrm{Pr} \\
\mathrm{Ti}\end{array}$}} & +++ & ns & ** & +++ & +++ \\
\hline & & & NS & NS & NS & + & NS \\
\hline \multicolumn{3}{|c|}{$\operatorname{Pr} \times \mathrm{Ti}$} & NS & NS & NS & NS & NS \\
\hline \multicolumn{3}{|c|}{ Do $\times \operatorname{Pr}$} & $*$ & $*$ & NS & NS & $* * *$ \\
\hline \multicolumn{3}{|c|}{$\mathrm{Do} \times \mathrm{Ti}$} & NS & $* *$ & NS & ** & NS \\
\hline \multicolumn{3}{|c|}{$\mathrm{Do} \times \operatorname{Pr} \times \mathrm{Ti}$} & $*$ & NS & NS & ** & NS \\
\hline
\end{tabular}


rapidly maturing crops that had partitioned relatively more dry matter to the tubers. Moreover, gamma-rays retarded crop maturation, causing a reduced amount of dry matter partitioned to the tubers at the time of harvest. The time between planting and emergence was not noticeably affected by treatment with the two lowest doses. In Trials 2 and 3, the time of $80 \%$ emergence was recorded (Tables 4 and $5)$.

With both cultivars, a distinct candelabra-like branching of the stems was observed in the field after the higher doses to the seed tubers (Figure 1). Irradiation damage to the apex of the growing sprouts may have allowed lateral buds to develop or caused a division of the apical meristem, leading to multiple branching. This point of ramification into 2 to 4 branches was observed at about $25 \mathrm{~cm}$ above the ground when tubers were irradiated on the day of planting. When the treatment took place before chitting, sprouts branched about $5 \mathrm{~cm}$ above the ground. With physiologically younger tubers at the time of irradiation, less internodes with lateral buds were apparently formed below the apex, thus giving rise to less stem elongation below the branching point. The reason for the different treatment dates in Trial 2 was to answer the question whether it would lead to a ramification of the stems before emergence and thus to a more substantial increase in the number of stems per plant. The results of the influence of the time of irradiation on plant characteristics is shown in Table 4 . Trial 2 was with Spunta only, because Bintje was not positively influenced by irradiation in Trial 1. The doses of 0.5 and $3 \mathrm{~Gy}$ were chosen, because

Table 4. Effects of time and dose of gamma-rays on growth and yield characteristics of cv. Spunta (Trial 2, 1989). See Tables 1 and 2 for experimental details and abbreviations.

\begin{tabular}{llllllll}
\hline $\begin{array}{l}\text { Dose } \\
\text { (Gy) }\end{array}$ & Time & $\begin{array}{l}\text { Number } \\
\text { tu/pl }\end{array}$ & $\begin{array}{l}\text { Number } \\
\text { st/pl }\end{array}$ & $\begin{array}{l}\text { Number } \\
\text { tu/st }\end{array}$ & $\begin{array}{l}\text { Weight } \\
(\mathrm{g}) / \mathrm{pl}\end{array}$ & HI & $\begin{array}{l}\text { Time of } 80 \% \\
\text { emergence } \\
\text { from planting }\end{array}$
\end{tabular}

\begin{tabular}{|c|c|c|c|c|c|c|c|}
\hline 0 & $\mathrm{~T} 1$ & 17.3 & 5.25 & 3.30 & 979 & 0.768 & 20.5 \\
\hline 0.5 & & 18.4 & 5.12 & 3.59 & 961 & 0.754 & 21.0 \\
\hline 3.0 & & 18.9 & 4.92 & 3.84 & 962 & 0.744 & 22.0 \\
\hline 0 & $\mathrm{~T} 2$ & 17.6 & 5.73 & 3.07 & 1055 & 0.759 & 21.3 \\
\hline 0.5 & & 18.5 & 4.90 & 3.78 & 1015 & 0.749 & 20.8 \\
\hline 3.0 & & 23.0 & 6.18 & 3.72 & 1116 & 0.755 & 22.0 \\
\hline 0 & T3 & 17.9 & 5.73 & 3.12 & 1109 & 0.744 & 21.0 \\
\hline 0.5 & & 19.5 & 5.88 & 3.32 & 1096 & 0.760 & 20.5 \\
\hline 3.0 & & 19.4 & 4.45 & 4.36 & 928 & 0.737 & 21.5 \\
\hline 0 & $\mathrm{~T} 4$ & 18.7 & 6.22 & 3.00 & 1051 & 0.768 & 21.0 \\
\hline 0.5 & & 18.9 & 5.23 & 3.61 & 1011 & 0.750 & 21.8 \\
\hline 3.0 & & 18.2 & 4.83 & 3.77 & 924 & 0.737 & 21.5 \\
\hline Do & & ++ & + & $*$ & $\mathrm{~ns}$ & $*$ & NS \\
\hline $\mathrm{Ti}$ & & ++ & ns & NS & + & NS & NS \\
\hline $\mathrm{Do} \times \mathrm{Ti}$ & & * & $* *$ & NS & $*$ & NS & NS \\
\hline
\end{tabular}


3 Gy was optimum in Trial 1 and might possibly be further reduced as to diminish the risk of mutations. The number of tubers per plant in Trial 2 increased with higher doses for the first three dates of irradiation. The largest number was observed when irradiation took place on the second date (1 November) in the year before planting. The increase in the number of tubers per plant was associated with an increase in the number of tubers per stem. The number of stems per plant, however, decreased with the exception of the dose $3 \mathrm{~Gy}$ at the second date. This may be explained by the subsoil ramification of the main stem, which led to a higher total number of tuber-bearing stems, resulting in a larger number of tubers per main stem. Tuber yield was slightly reduced with $3 \mathrm{~Gy}$ but only in the later treatments, due to slightly reduced harvest index.

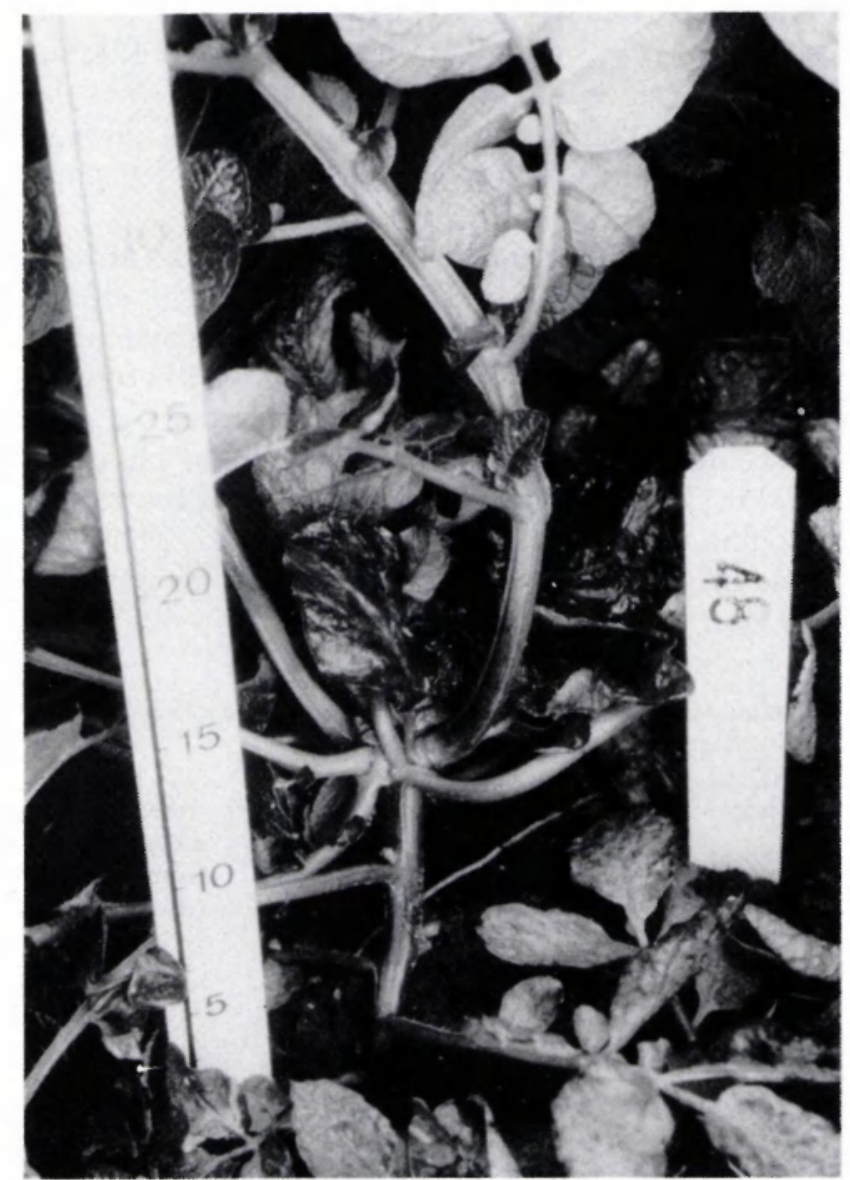

Fig. 1. Candelabra-like branching of the stem after treatment of the seed tuber with a dose of gammarays of 9 Gy before chitting (cv. Bintje). 
Trial 3 attempted to confirm the results found so far for the cultivar Spunta and with Jaerla, another cultivar producing notoriously few tubers. The seed tubers were therefore treated with 0,3 or $10 \mathrm{~Gy}$ on 25 October 1989 . The highest dose was applied because of an interaction with the time of application, which possibly allowed recovery of the ability to form increased number of stems. In Trial 3, the cultivar Spunta did not react to the treatments (Table 5) and the cultivar Jaerla only had more tubers per plant when treated with $3 \mathrm{~Gy}$. Increased doses for Jaerla increased number of stems and decreased number of tubers per stem. The combination increased number of tubers per plant only with $3 \mathrm{~Gy}$. The apparently contradictory results for effects of gamma-rays on stems per plant and tubers per stem for Jaerla (Table 5) and for Spunta (Table 4) may be due to the way in which the number of stems was determined. For Jaerla, underground branching near the parent tuber may have been counted as separate stems, though they may have originated from the same sprout. Two or more stems might possibly have left one single wound on the mother tuber upon detachment. It was not clear why Spunta was not influenced by gamma-rays in Trial 3. The main difference from Trials 1 and 2 was the three-day shock treatment with warmth before chitting. This effect is known to speed up the breaking of tuber dormancy and may have erased the effect of gammarays on the seed tuber.

The number of main stems formed per tuber is mainly determined by the physiological age of the tuber (e.g. Haverkort et al., 1990a). The soil conditions (moisture and temperature) before emergence may play a role but these were the same for all treatments within each trial, since doses of gamma-rays less than 27 Gy hardly affected the time from planting to emergence. The number of tubers formed per stem largely depends on the moisture content of the soil at the time of stolon and tuber initiation (Haverkort et al., 1990b). The influence of gamma-rays on the parent tuber at the outset of tuber initiation was not determined in this study. The plots were irrigated frequently to avoid drought stress and an influence of the environment was therefore not likely.

Table 5. Effects of dose of irradiation on growth and yield characteristics of cv. Spunta and Jaerla (Trial 3,1990 ). See Tables 1 and 2 for experimental details and abbreviations.

\begin{tabular}{llllllll}
\hline $\begin{array}{l}\text { Dose } \\
\text { (Gy) }\end{array}$ & Cultivar & $\begin{array}{l}\text { Number } \\
\text { tu/pl }\end{array}$ & $\begin{array}{l}\text { Number } \\
\text { st/pl }\end{array}$ & $\begin{array}{l}\text { Number } \\
\text { tu/st }\end{array}$ & $\begin{array}{l}\text { Weight } \\
(\mathrm{g}) / \mathrm{pl}\end{array}$ & HI & $\begin{array}{l}\text { Time of 80\% } \\
\text { emergence } \\
\text { from planting } \\
(\mathrm{d})\end{array}$ \\
& Spunta & 13.4 & 4.46 & 3.14 & 1332 & 0.791 & 20.8 \\
0 & & 13.2 & 4.11 & 3.25 & 1369 & 0.785 & 21.3 \\
3 & 13.2 & 3.82 & 3.53 & 1322 & 0.768 & 21.8 \\
10 & & & & & & & \\
& Jaerla & 8.21 & 2.74 & 2.95 & 1264 & 0.846 & 21.3 \\
0 & 9.62 & 3.03 & 3.18 & 1258 & 0.828 & 23.3 \\
3 & & 8.17 & 3.61 & 2.30 & 1144 & 0.802 & 25.8 \\
\hline 10 & & NS & NS & NS & NS & NS & NS \\
\hline $\begin{array}{l}\text { Spunta } \\
\text { Jaerla }\end{array}$ & & $* *$ & $*$ & NS & NS & $*$ \\
\hline
\end{tabular}




\section{Conclusions}

Gamma-rays did not consistently increase the number of tubers per plant. The best results led to a $30 \%$ increase, which is comparable to the use of physiologically young seed tubers (Haverkort et al., 1990a) or to the application of gibberellic acid to the crop (Bodlaender \& van de Waart, 1989). The latter two methods, however, are preferred because they may represent more reliable methods to increase the number of tubers. The cultivar Bintje, which normally produces a rather large number of tubers per plant, did not increase its number of tubers when its seed potatoes were treated with $3 \mathrm{~Gy}$. Irradiation of the seed tubers of the cultivar Spunta with 3 Gy led to a larger number of tubers per plant in two out of three trials. Treatment was more successful when the time from treatment to planting was longer (about 5 months) and when the seed tubers were allowed to produce fully developed sprouts before planting. In such conditions, the cultivar Jaerla also yielded more tubers in Trial 4. Higher doses, of 9 or $10 \mathrm{~Gy}$, did not increase number of tubers and a dose of $27 \mathrm{~Gy}$ resulted in off-type plants and a drastic decline in yield and number of tubers. Low doses given months before planting did not lead to slower emerging plants. The reduced harvest index after high doses seem indicative of a retarded tuber initiation or of later maturing. The increase in number of tubers with gamma-rays involved termination of growth of the apex of the growing sprout, allowing lateral buds to develop into stems. If tubers were irradiated when sprouts started growing, few lateral buds were present under the apex resulting in branching of the sprout near the mother tuber, leading to plants with a larger number of stems. These stems could not be clearly determined as main stems or lateral stems. In the seed potato industry, the use of gamma-rays may not compete with the use of physiologically younger seed tubers or with the application of growth substances such as gibberellic acid, because of the greater reliability of those methods.

\section{Acknowledgements}

We gratefully acknowledge technical assistance by $\mathrm{Mr} \mathrm{H}$. Peeters.

\section{References}

Bodlaender, K. B. A. \& M. van de Waart, 1989. Influence of gibberellic acid (GA3) applied to the crop on growth, yield and tuber size distribution of seed potatoes. Netherlands Journal of Agricultural Science 37: 185-196.

Cotter, D. J. \& R. L. Sawyer, 1961. The effect of gamma irradiation on the incidence of black spot, and ascorbic acid, glutathione and tyrosinase content of potato tubers. American Potato Journal 38: 58-65.

Fischnich, O., C. Paetzold \& F. Heilinger, 1961. Influence of low doses of irradiation (X-rays and gamma rays of cobalt-60) on potato seed. Effects of ionizing radiations on seeds, p. 553-564. IAEA, Vienna.

Haverkort, A. J., M. van de Waart \& K. B. A. Bodlaender, 1990a. Effect of preplanting temperature and light treatments of seed tubers on potato yield and tuber size distribution. Potato Research 33: 77 88.

Haverkort, A. J., M. van de Waart \& K. B. A. Bodlaender, 1990b. The effect of early drought stress on numbers of tubers and stolons of potato in controlled and field conditions. Potato Research 33: 89-96. 


\section{A. J. HAVERKORT, D. I. LANGERAK AND M. VAN DE WAART}

Heilinger, F., C. Paetzold, W. Scheid, O. Siegel \& A. Suess, 1967. Auswirkung der Pflanzgutbehandlung mit ionisierenden Strahlen auf Entwicklung und Ertrag von Kartoffeln. European Potato Journal 10: $180-188$.

Sawyer, R. L. \& S. L. Dallyn, 1961. Effect of irradiation on storage quality of potatoes. American Potato Journal 38: 227-235.

Sparks, W. C. \& W. M. Iritani, 1964. The effect of gamma rays from fission product wastes on storage losses of Russet Burbank potatoes. Idaho Agricultural Research Station Bulletin 60: 27-35.

Voropaev, Y. V., L. S. Lure, V. T. Parvenov \& V. S. Serebrenikov, 1968. The effect of different doses of gamma irradiation on potato plants. Radiobiologiya 8: 635-637.

Wills, P.A., 1965. Some effects of gamma radiation on several variaties of Tasmanian potatoes. 1. Storage problems. 2. Biochemical changes. Australian Journal of Experimental Agriculture and Animal Husbandry 5: 282-288. 